\title{
MULHERES DE TERREIRO E PATRIARCADO: UMA PROPOSTA DE REFLEXÃO
}

\author{
Ariadne Moreira Basílio de Oliveira ${ }^{1}$ \\ DOI 10.26512/revistacalundu.v4i1.32232
}

\begin{abstract}
Resumo
As comunidades de terreiro são espaços que agregam valores e formas próprias de produção e transmissão de conhecimento, relações pessoais e políticas, maneiras de ver, sentir e compreender o mundo, organização social e relações de gênero, como maneiras de religar os contextos comunitários e identitários que foram esfacelados pela colonização e pela escravização. A sociedade brasileira, por sua vez, foi forjada através da colonização portuguesa e da imposição dos valores morais, científicos, normativos europeus ocidentais que possuem em seu cerne e como sua base o patriarcado. Considerando que as comunidades de terreiro estão imersas dentro da sociedade brasileira e dela fazem parte, o objetivo deste texto é trazer um questionamento sobre como o patriarcado brasileiro tem influenciado as comunidades de terreiro, a partir de uma revisão das obras que retratam esse tema, e também um chamado para uma reflexão sobre a importância da compreensão das comunidades afro-religiosas para que haja atenção aos artefatos, teorias e formas de leitura que lançamos mão para significarmos a influência do patriarcado dentro dessas comunidades.
\end{abstract}

Palavras-chave: Mulheres de terreiro. Patriarcado. Religiões Afro-brasileiras. Comunidades de Terreiro.

\section{MUJERES DE TERREIRO Y PATRIARCADO: UNA PROPUESTA DE REFLEXIÓN}

\begin{abstract}
Resumen
Las comunidades terreiro son espacios que agregan valores y formas de producir y transmitir conocimiento, relaciones personales y políticas, formas de ver, sentir y comprender el mundo, organización social y relaciones de género, como formas de reconectar contextos comunitarios e identitarios que fueron destrozados por la colonización y la esclavitud. La sociedad brasileña, a su vez, se forjó mediante la colonización portuguesa y la imposición de valores morales, científicos y normativos de la Europa occidental, que tienen en su núcleo el patriarcado como base. Teniendo en cuenta que las comunidades terreiro están inmersas dentro, y son parte de la sociedad brasileña, el objetivo de este texto es plantear una pregunta sobre cómo el patriarcado
\end{abstract}

\footnotetext{
${ }^{1}$ Mestra em Direitos Humanos e Cidadania pela Universidade de Brasília - UnB, desenvolvi minha pesquisa sobre racismo religioso. Bacharela em Ciência Política pela Universidade de Brasília, com experiência na área de Educação política, Direitos Humanos e Religiões Afro - brasileiras. Membra do Calundu - Grupo de Estudos sobre Religiões Afro- brasileiras e parte da Equipe Editorial da Revista Calundu.
} 
brasileño ha influido en las comunidades terreiro, basándose en una revisión de los trabajos que retratan este tema, y también un llamado a la reflexión sobre la importancia de comprender las comunidades afro-religiosas para que se preste atención a los artefactos, teorías y formas de lectura que usamos para significar la influencia del patriarcado dentro de esas comunidades.

Palabras-clave: Mujeres de Terreiro. Patriarcado. Religiones Afro-brasileñas. Comunidades de Terreiro.

\section{Yalodê}

Inicio a apresentação desse artigo trazendo um oriki bastante conhecido dentro dos terreiros de candomblé.

Como nos conta Mãe Jaciara de $\mathrm{Oxum}^{2}$, os orixás logo que chegaram à terra, organizaram grandes reuniões para deliberarem sobre questões concernentes a ela, contudo, proibiram a presença de mulheres nessas reuniões. Então, apesar das deliberações e organizações tomadas a partir das reuniões, a terra não estava bem. Os rios secaram, as mulheres se tornaram inférteis, a natureza não dava um retorno à comunidade. Foi aí que esses orixás procuraram Oduduwa ${ }^{3}$ para saber o que estava acontecendo e contaram que, apesar das reuniões, os seus esforços não estavam dando certo. Então, Oduduwa perguntou: Oxum faz parte dessa reunião? Os orixás responderam que não. E tornou-se evidente que a falta de Oxum estava acarretando esses problemas. Os orixás pediram, então, que Oxum comparecesse às reuniões e depois de muito insistirem ela aceitou. Os rios voltaram a correr, as mulheres a engravidar, a terra a ser produtiva. Assim, Oxum ganhou o título de Yalodê, que é um título de grande poder e significa senhora da cidade.

Mãe Jaciara, após a conclusão do oriki, transfere seu sentido aos nossos dias, salientando a importância e o poder da mulher que no candomblé se reflete em sua posição lado a lado com os homens.

Compreendendo que os orikis, itans, são formas de contar os enredos mitológicos que abarcam não só uma visão do passado, como também a compreensão das dinâmicas sociais e mesmo políticas do presente (SEGATO, 2007), ressaltando

\footnotetext{
${ }^{2}$ Vídeo disponível no YouTube com o Título: Mulheres de Axé - Vozes contra a Intolerância. Tal vídeo faz parte de um projeto realizado pela ONG Ação pela Cidadania em conjunto com o Ilê Axé Oxumarê, Associação beneficente Abassá de Ogun, Associação Comunitária Alzira do Conforto, Coletivo de Entidades Negras e Água de meninos, com o apoio da Secretaria de Políticas para as Mulheres do governo da Bahia. <https://www.youtube.com/watch?v=qbgoqgoBiKU\&t=311s>

${ }^{3}$ Em algumas versões desse oriki é contado como sendo Olódùmarè, o ser supremo que também é chamado de Olorun, o senhor do céu.
} 
também a importância da transmissão desse conhecimento através da oralidade, evidente está o papel e a posição das mulheres nas dinâmicas das comunidades de terreiro, como também na ordem e funcionamento do mundo para essas comunidades.

Sendo as denominadas religiões afro-brasileiras forjadas no Brasil com a vinda forçada de africanos e africanas de diversas etnias, para trabalharem em regime de escravidão, proporcionaram não só um ambiente de culto religioso, mas também a formação de comunidades que agregam valores e formas próprias de produção e transmissão de conhecimento, relações pessoais e políticas, maneiras de ver, sentir e compreender o mundo, organização social e relações de gênero, proporcionam ainda, maneiras de religar os contextos comunitários e identitários que foram esfacelados pela colonização e escravização (NASCIMENTO, 2016). As comunidades de terreiro são, portanto, mais do que expressões religiosas e abrigam em seu interior maneiras distintas da sociedade moderna ser e reexistir no mundo.

Entretanto, essas comunidades com prerrogativas de modo de vida próprio estão inseridas dentro de uma "dupla pertença", sendo uma envolvida por relações comunitárias, nos terreiros, e outra individualista caracterizada pela sociedade ocidental moderna (NASCIMENTO, 2016). Essa diferenciação faz parte das fissuras abertas pela modernidade por aquelas sociedades e comunidades que destoam do apregoado pela imposição moderna (BHABHA, 1998; SEGATO, 2012). Portanto a existência dessas comunidades em si já representa a resistência de um povo em sua complexidade. São construções disfuncionais ao capital (SEGATO, 2015, 2016).

É a partir da compreensão de uma dupla inserção, de um caminhar entre dois mundos, que insiro o objetivo deste artigo como uma busca questionadora, quase ensaística, em compreender de que forma o patriarcado brasileiro influi nos papéis sociais e rituais das mulheres dentro dos terreiros de candomblé.

\section{Yalorixás, Babalorixás e o patriarcado}

Compreendendo o patriarcado moderno como estruturador das relações sociais e institucionais das sociedades ocidentais modernas em sua intersecção com a construção social da raça em uma associação de sistemas de subordinação e discriminação (CRENSHAW, 2002), este finda por "menorizar" a mulher, relegando-a ao domínio privado ao mesmo tempo em que constitui a esfera pública como área exclusiva de homens brancos, retirando a diversidade e atuação antes presente na vida comunitária 
concluindo, assim, a posição de inferiorização da mulher frente a sociedade moderna (SEGATO, 2015).

Nessa esteira de hierarquização e inferiorização da mulher a partir da intersecção com a raça, é ainda mais vulnerável a situação das mulheres não-brancas, colocadas no mais baixo degrau de uma escalada evolucionista da sociedade que culminaria com a figura do homem branco em seu topo (LUGONES, 2008; BIDASECA, 2013). O patriarcado constitui-se, portanto, enquanto lógica de dominação e subjugação.

Corroborando com a distinção preeminente entre as comunidades de terreiro e da sociedade moderna, situo aqui a construção dos primeiros candomblés em Salvador, Bahia, que tiveram os seus cultos organizados de forma a corresponderem ao que chamamos de candomblé no século XIX e que possuíam na sua formulação a organização social e comunitária em torno da mãe de santo e de seus filhos e filhas (SILVEIRA, 2006). Transmutado como um espaço doméstico o espaço do terreiro expressa suas variadas formas e compreensões rituais, artísticas, políticas e sociais (SEGATO, 2005, 2007).

A importância da mulher nesses espaços, que inicialmente eram a grande maioria das líderes dessas comunidades, as mães de santo, destoa das lideranças tanto sociais quanto religiosas em outras esferas da sociedade mais abrangente, ou seja, da sociedade brasileira constituída a partir da colonial modernidade ocidental. Ainda mais proeminente e destoante é o fato de que as mães de santo líderes dos terreiros eram, e em grande parte ainda são, mulheres negras que, dentro da visão e estruturação de uma sociedade patriarcal e racista, ocupam um lugar caracterizado pela ausência de prestígio na sociedade mais abrangente.

As mulheres nos terreiros podem, portanto, diferentemente de outras religiões, alçarem o mais alto escalão de liderança dentro dos terreiros, a de Mãe de Santo de sua comunidade. O papel da mulher na estruturação dessas comunidades é histórico, pois remete ao fato de que foram elas, a partir do comércio de alimentos, produtos e bens, quem foram capazes de comprar as suas alforrias, assim como a de suas próximas, sejam essas de vínculos parentais sanguíneos ou não, e também compraram e estruturam os espaços onde foram organizadas suas comunidades (LANDES, 1947/1967; SEGATO, 1986/2005). Foi a partir da família de santo que as comunidades de terreiro foram estruturadas, e dentro dessa família, foi a partir das Mães de Santo que, através 
dos rituais de iniciação, foram criados os vínculos parentais entre a comunidade estabelecida. (SEGATO, 2005)

Contudo, na esteira de trabalhos que tentam levantar a discussão de gênero nos terreiros, existem recentes pesquisam que afirmam que as mulheres de terreiro, ou mulheres de axé, como se autodenominam, têm perdido espaço e poder fora de seus terreiros (CORDOVIL, 2013; SOUZA, 2014). Antes conhecidas como grandes mulheres de seu tempo, hoje estariam perdendo essa prerrogativa para a maior atuação de lideranças masculinas nas comunidades de terreiro (SARDUY, 2015).

$\mathrm{O}$ fato do aumento do número de homens ocupando o cargo mais alto na hierarquia dos terreiros, como Pais de Santo, não deve ser encarado em si como algo que afirme o domínio e sobreposição dos homens nesses cultos, já que a posição de Pai e Mãe de Santo são equivalentes não há nada que um faça que a outra não poderia fazer em se tratando deste cargo de liderança comunitária (SEGATO, 2003, 2005). Contudo, o grande número de Pais de Santo como líderes pode indicar um maior prestígio de homens nessa posição o que incita um questionamento sobre a influência do patriarcado nessas construções quase intuitivo.

Para a continuidade dessa reflexão, faz-se necessária uma pequena volta à construção da sociedade moderna para compreensão do patriarcado como base de onde é forjada essa mesma sociedade.

\section{Colonialidade e patriarcado na construção da sociedade moderna}

A conquista e a colonização das Américas estiveram imbuídas dos arranjos sociais, políticos, econômicos e religiosos presente nas estruturas das sociedades que empreenderam a colonização.

Quando o europeu vem para a América com o intuito de conquistar e colonizar, ele traz consigo todo seu aporte social que estava sendo desenvolvido em sua região, ou seja, no caso especial das colonizações perpetradas pelos países da península ibérica, os valores construídos naquelas sociedades e que foram expressos pelos colonizadores, tinham como características um sentido de conquista militar, violenta, que envolveram guerras, em decorrência dos anos da "reconquista"; uma grande força moral cristã e de cunho evangelizador e missionário devido a forte expressão de poder dos reis católicos e sua empreitada na contrarreforma; uma base social patriarcal de subordinação e invisibilização da mulher; uma moral homogeneizadora da sociedade segundo preceitos cristãos; e a exploração econômica com o intuito da acumulação de riqueza e para 
incremento da demonstração de poder frente as outras sociedades. Foram essas características, portanto, que fundaram a forma da colonização na América Latina. (Oliveira, 2017. p. 49-50)

Essa forma de colonização e os processos a partir delas desencadeados proporcionaram a própria construção do que hoje se denomina de Europa, forjada como centro a partir da delimitação da América como periferia. Essa posição relacional também influenciou na forma com que foi desenvolvido o padrão de poder mundial como desdobramento de um padrão de poder eurocentrado (QUIJANO, 2005a, GESCO, 2012).

A construção do padrão de poder inscrito nesta colonialidade imprescinde da racialização da sociedade, excluindo da construção de mecanismos de poder e instituições as populações não-brancas (QUIJANO, 2005a, 2005b).33

Em intersecção com a construção social inferiorizante presente na categorização de raça tem-se o patriarcado que, sob os moldes capitalistas, também estruturara o padrão colonial de poder. As economias de mercado capitalistas também contaram com as divisões de gênero, determinadas pelo patriarcado, e de raça nas dinâmicas do desenvolvimento do capitalismo e em sua forma organizativa forjada a partir da modernidade (LUGONES, 2008).

A confluência da racialização da população e da divisão desta através do gênero, a partir de uma imposição do patriarcado heterossexual, também permeou a construção da racionalidade moderna que foi formulada a partir de binarismos e dicotomias, de forma a delimitar o papel social da mulher atrelando-a ao âmbito do corpo, do objeto, do sexo, em oposição ao do homem branco como sujeito e imbuído de razão (SEGATO, 2012, 2015).

Todas essas formas confluentes de exploração desempenhadas através da conquista, colonização, estruturação de um mercado capitalista, divisão de trabalho e formulação dos preceitos científicos passaram por uma compreensão e estruturação patriarcal da sociedade. Isso demonstra a importância da compreensão do "sistema de gênero" (SEGATO, 2015) para a apreensão de vários de nossos fenômenos sociais.

Segundo a antropóloga Rita Segato (2012, 2015), a construção da esfera pública como domínio universal representado pelo homem branco foi erigida em detrimento dos espaços domésticos presentes no que a autora denominou de "mundo aldeia", que seria o mundo pré-intrusão colonial. 
Nesse processo o espaço doméstico, antes diverso e com funcionamento em complementariedade a demais espaços e, sobretudo, ao público, foi relegado ao âmbito privado e sofreu o que a autora denominou de "menorização" de tudo que concerne as mulheres. Com isso, Segato conclui que a história da denominada esfera pública é a história do patriarcado, e afere:

Defiendo aquí que comprender las transformaciones del "sistema de género" y la historia de la estructura patriarcal arroja una luz indispensable para entender el giro social introducido por la modernidad como un todo. Si leemos adecuadamente lo que ese tránsito significó y la forma en que la intervención reacomodó y agravó las jerarquías preexistentes, comprenderemos una cantidad de fenómenos del presente que afectan a toda la sociedad y que están muy lejos de constituir apenas "el problema de la mujer" (SEGATO, 2015. p. 2)

A matriz do patriarcado está presente na gramática estatal, como explicitam Tânia Mara de Almeida e Lourdes Bandeira:

a disseminação de uma linguagem masculina exclusivista está introjetada nas estruturas socioinstitucionais e jurídicas. Tais situações de poder, em relação ao referente masculino, se fazem presentes no planejamento das ações públicas mesmo em governos que se comprometem com a redução das desigualdades de gênero (BANDEIRA, ALMEIDA, 2013, p. 38).

Assim, institucionalizado a partir da conquista e decorrente colonização das Américas sendo constitutivo do poder colonial que, posteriormente, alça outras regiões do globo, o patriarcado, em intersecção com as discriminações advindas pela construção social da raça, é perpetuado atualmente pela institucionalidade estatal que deriva da construção da colonialidade moderna.

\section{Mulheres de terreiro}

Quando o tema se refere aos cultos afro-brasileiros é possível encontrar uma vasta bibliografia, especialmente as de cunho antropológico, psicológico e sociológico. Contudo, quando se trata do tema de gênero dentro dessas abordagens, a bibliografia se mostra mais restrita. Com relação a textos que destacam a atuação e papéis sociais desempenhados pelas mulheres dentro de suas relações rituais, sociais e de gênero essa é ainda menor. 
Ruth Landes (1947-1967) é a primeira autora a abordar a questão do gênero no candomblé, mas, expressamente, traz em seu trabalho a afirmação de que os candomblés da cidade de Salvador, na Bahia, funcionavam sobre o regime de matriarcado em que as mulheres tinham plenos poderes e independência com relação aos homens.

Segundo Landes as mulheres negras na Bahia, devido à forma com que se desenvolveu a escravidão nessa região, tiveram mais oportunidades de trabalho como domésticas na casa grande, escravas de ganho, cozinheiras, lavadeiras, entre outras tarefas que permitiram com que elas conseguissem maior espaço para uma remuneração de seus trabalhos especialmente após a abolição (1967, p. 87, 312, 313). Assim, as mulheres foram as que conseguiram juntar dinheiro para a compra de sua alforria como também as de seus companheiros e demais familiares ou amigos. Também foram elas que conseguiram a compra dos terrenos onde foram construídos os terreiros sob sua liderança. Eram mulheres independentes dos homens (1967, p. 48, 163).

As mulheres tinham pleno domínio e poder sobre seus terreiros e os homens tinham um papel secundário ao da Mãe de Santo dentro deles. Segundo Landes, a partir de seu interlocutor Edison Carneiro, os Ogãs (homens iniciados que não entram em transe) eram provedores e protetores dos terreiros. Chamados de pai, eles possuíam uma posição alta na hierarquia dos terreiros, contudo se mantendo abaixo das Mães de Santo. Os que não possuíam o cargo honorífico de protetores e financiadores desempenhavam papeis rituais como tocadores de atabaque, sacrificadores e auxiliadores, sempre sobre as ordens da Mãe de Santo (1967, p.42, 55, 161, 289).

Ainda segundo Ruth Landes, os homens em posição de Pais de Santo não eram tolerados nas casas de Candomblés Nagôs na época da realização de sua pesquisa, somente desempenhando tais funções em Candomblés Angolas e em Candomblés de Caboclo $^{4}$ (1967, p.44, 45).

Seu trabalho, denominado "A cidade das mulheres", foi duramente criticado por autores como Arthur Ramos (1942), e Herskovits (1947), devido suas afirmações sobre o matriarcado e a homossexualidade nos candomblés (1967, p.55, 86, 291, 292, 314). Arthur Ramos, em especial, presava por uma interpretação mais cristã dos cultos para que tivessem o reconhecimento enquanto religiões dentro da sociedade brasileira.

\footnotetext{
${ }^{4}$ As diferentes denominações de candomblés referem-se às especificidades de cada um concernentes as etnias que tiveram maior peso em sua estruturação. Mais sobre o assunto em: Nascimento, Wanderson Flor do. Sobre os candomblés como modo de vida: Imagens filosóficas entre Áfricas e Brasis (2016)
} 
Posteriormente outros trabalhos ainda trouxeram a temática da homossexualidade, como Herskovits (1947), Bastide (1971) e Fry (1982), contudo, os dois primeiros a abordam de forma bastante preconceituosa e o último se ateve a homossexualidade masculina.

O trabalho de Rita Segato (1986/2005) também traz uma abordagem de fôlego sobre as mulheres nos cultos afro-brasileiros. A autora efetivamente estudou os Xangôs do Recife, mas logrou alcançar resultados também aplicáveis ao Candomblé. Ela salienta, em concordância com o que alegou Ruth Landes (1967), que as mulheres negras tiveram mais oportunidades e de certa forma sofreram menos com a escravidão que os homens negros e essa maior participação em tarefas remuneradas e grande contato com as famílias brancas e os senhores patriarcais fez com que desenvolvessem mais tato para as atuações como comerciantes ${ }^{5}$. Foi assim que conseguiram obter seus terrenos para a construção de seus terreiros (2005, p. 453). E foi em torno da categoria da Mãe que foram formadas as famílias de santo que criadas como uma forma de reestabelecer os vínculos familiares destruídos pelas práticas no período escravocrata que apartavam famílias, desestimulavam o casamento entre escravos e vendiam os filhos de suas relações (idem, p. 431, 432, 438, 439, 455, 461).

Rita Segato foi a primeira autora ${ }^{6}$ a explicitar as relações homossexuais entre mulheres de terreiro e assumi-las como parte formante das comunidades (ibidem, p. 422, 423, 445, 446, 460). Apesar de fazer a ressalva de que o que ela identificou pode estar presente só no Xangô do Recife, Segato traz a complexidade e a fluidez das construções de gênero entre as mulheres e homens dessas comunidades (ibidem, p. 427, 465, 466). Além disso, traz a divisão de papeis rituais como sendo separados de acordo com o sexo biológico e não com o gênero (ibidem p. 442, 443). Os papeis desempenhados por homens seriam complementares aos desempenhados pelas mulheres e não teriam em si uma hierarquização. Assim, não há distinção entre a Mãe de Santo, que é líder do terreiro, e de um Pai de Santo, também como líder de seu terreiro, o que garante um equilíbrio entre os papeis e poderes desempenhados (ibidem p. 442).

\footnotetext{
5 Deixo aqui a ressalva de que essa afirmação de que as mulheres negras sofreram menos com a escravidão é uma afirmação, ao meu ver, infeliz (SEGATO 2005 e LANDES 1967). O fato de poderem desenvolver o tato para o comércio não é algo que possa apagar as perversidades que o regime escravrocrata brasileiro infringiu às mulheres negras. Não se trata de um ranqueamento de sofrimentos toleráveis.

6 Ruth Landes (1967) alude à questão do homossexualismo feminino, contudo sem dar maiores informações. Seu foco é na homossexualidade masculina.
} 
Segato questiona a assunção do modelo matriarcal de Landes em terreiros e famílias de santo, propondo ser mais adequado pensarmos em famílias matrifocais, ou famílias estendidas afro-caribenhas/americanas (2005, p. 436, 437, 440).

Continuando na discussão das autoras que trazem uma abordagem com um foco maior sobre as mulheres e suas relações nas religiões afro-brasileiras, Patrícia Birman (1995), através da orientação de Peter Fry, traz uma abordagem de gênero relacionada a características das possessões das religiões afro-brasileiras.

Em seu argumento para a compleição da sua pesquisa, a autora vai além do que Ruth Landes descreve, em tom ainda bastante preconceituoso, sobre a homossexualidade nos terreiros. Segundo Birman (1995) as possessões estariam veiculadas às mulheres ou a homens feminilizados, pois a possessão estaria associada a uma possível emasculação do homem, ao passo que traria um empoderamento à mulher $(1995,2005)$.

As mulheres nos cultos afro-brasileiros desempenhariam, assim, grande parte das tarefas relacionadas aos rituais nos terreiros e estariam também mais empenhadas no resguardo da tradição ao passo que os Pais de Santo que lideram terreiros estão mais abertos para as questões mundanas. (1995, p. 56)

Trabalhos e pesquisas mais atuais tratam da importância e do poder das mulheres de terreiro. Divido esses trabalhos em duas frentes: uma que traz reflexões sobre a continuidade da importância das mães de santo nos terreiros como um continuum e reflexo de trabalhos anteriores que se embasaram nessa afirmativa. (SILVA, DOMINGOS, 2009; SILVA, OLIVEIRA, CAMPOS, 2009; VILELA, 2016; CORREIA, 2017). E outra frente que se mostra de maneira mais crítica com relação os papéis sociais e rituais desenvolvidos por mulheres nos terreiros, e trazem inclusive uma diferenciação histórica entre dinâmicas das comunidades de terreiro (FERRETI, 2007; CORDOVIL, 2013; SOUZA, 2014; SARDUY, 2015). Dentre esses trabalhos quero destacar aqui três deles que auxiliam no debate atual e também no questionamento que estimula a construção deste artigo.

No primeiro desses trabalhos, Daniela Cordovil (2013) busca identificar o papel que as mulheres de terreiro assumem frente à política dos afro-religiosos. A autora especifica que sua abordagem se restringe a atuação política das mulheres na sociedade mais abrangente. Como conclusão de sua pesquisa afirma que apesar do grande número de lideranças femininas que se envolvem na construção de políticas públicas, as 
mulheres de axé ainda, em sua maioria, tendem a assumir um papel secundário nos espaços políticos, ou sendo respaldadas por homens, como os Ogãs, ou tendo um reconhecimento inferior de sua atuação.

É necessário salientar que a autora coloca como esfera política somente a relacionada ao Estado e aqui cabe ressaltar que, apesar de sua aparente domesticidade, concordo com Segato (2007) quando ela afirma que os terreiros também são espaços políticos. Todavia, é importante considerar a conclusão da pesquisa citada, uma vez que abre questionamentos sobre o poder desempenhado pelas mulheres de terreiros, antes referenciadas por Landes como matriarcas e plenas de poder no espaço do terreiro e fora dele.

O segundo trabalho que destaco é o de Nadson Nei da Silva de Souza (2014). Este se refere de maneira mais aprofundada com relação às mulheres de terreiro e expõe, por meio de uma etnografia em um terreiro de candomblé em Maricá, Rio de Janeiro/RJ, como as mulheres ainda têm um papel importante nas atuações desempenhadas dentro dos terreiros enquanto são pouquíssimas aquelas que também têm uma visibilidade de suas atuações fora destes espaços (SOUZA, 2014).

Por fim, o terceiro trabalho é o de Aída Esther Bueno Sarduy (2015), antropóloga cubana, que fez a pesquisa de sua tese doutoral em Recife com as comunidades de Xangô, e traz uma conclusão bastante perturbadora se consideramos o histórico dessas comunidades com relação ao poder das mulheres nesses espaços.

A autora afirma que o Recife também teria sido uma cidade das mulheres, como afirmou Landes com relação à cidade de Salvador (2015, p.134, 329). Contudo, hoje a maioria das lideranças nos terreiros tradicionais de Xangô são desempenhadas por homens, fato que por si já denota uma mudança na configuração atual dos terreiros (2015, p.135, 329). Além disso, a autora afirma que os trabalhos realizados exclusivamente por homens no Xangô, como o jogo divinatório de Opelê Ifá e sua "mão de faca", ou seja, o poder de desempenhar sacrifícios rituais, seriam valorizados pelo simples fato de serem desempenhadas por homens, seguindo assim uma lógica da sociedade machista ocidental $(2015$, p. $92,135,136,137,140)$.

Os trabalhos desempenhados por mulheres nessas comunidades estariam vinculados a tarefas domésticas e parecem não ter o mesmo prestígio que as tarefas desempenhadas pelos homens, comparação que a autora faz com relação a remuneração recebida pelos serviços e trabalhos realizados por pais de santo, que são altamente 
remunerados, enquanto as mulheres que ficam com grande parte dos afazeres dentro da casa de santo não gozariam de mesma remuneração, recebendo somente ajudas de custo com o transporte, por exemplo (2015, p.135, 136, 141, 333).

As três últimas argumentações e conclusões presentes nos trabalhos citados acima têm em comum a referência ao machismo e às relações patriarcais da sociedade mais abrangente como influenciadoras das comunidades de terreiro em relação à perda de poder das mulheres nesses espaços.

\section{O problema do uso do conceito que se quer criticar}

As conclusões das últimas três pesquisas citadas anteriormente despertam uma cadeia de questionamentos sobre os papeis desenvolvidos pelas mulheres nas comunidades de terreiro.

Apesar de compartilhar da compreensão de que as mulheres de terreiro estão perdendo poder frente à esfera pública e que o número de homens como pais de santo líderes de terreiro têm aumentado, denotando em si uma menor atuação das mulheres nessas posições, foi a partir da confrontação de como se dá a organização de um terreiro de Candomblé que os questionamentos que direcionam este artigo foram suscitados.

Enquanto nas comunidades de Xangô recifense, segundo Sarduy (2015), os homens seriam os únicos a desempenharem o papel de adivinhos a partir do domínio de Opelê Ifá e os únicos que poderiam sacrificar animais nos cultos, nos Candomblés Ketu e Angola é possível que as mulheres desempenhem esses mesmos papeis, fazendo com que os homens sejam dispensáveis.

Existe o cargo de Axogun ou Kivonda, que é um cargo desempenhado por um Ogã nos candomblés Ketu e Angola, respectivamente, responsável pelos sacrifícios rituais. Entretanto, as mulheres iniciadas que possuem em seu destino a responsabilidade para desempenhar o cargo de Mãe de Santo de uma comunidade religiosa podem adquirir a "mão de faca" e dispensá-los.

Já com relação ao jogo divinatório, desde a época em que Ruth Landes fez sua pesquisa na cidade de Salvador, na década de 1930, as mães de santo dos Candomblés já tinham domínio do jogo de búzios como oráculo. Centrado em Exú, o jogo de búzios foi uma estratégia das mães de santo para dialogarem com suas divindades e não dependerem necessariamente de um Babalaô, cargo ocupado por homens, que teriam o domínio do Oráculos de Ifá. Landes (1967) aponta em sua obra que o número de 
Babalaôs que desempenhavam bem sua função estava cada vez mais escasso e que as Mães de Santo acabaram por organizar suas próprias estratégias para que não fossem necessários para a divinação ritual.

Com relação ao ganho de alta remuneração ligada aos pais de santo recifenses, paira uma dúvida sobre se essas remunerações não fariam parte do lugar ocupado de líder do terreiro e, portanto, a quem se procura para tratar, cuidar e curar, sendo essa a origem da sua remuneração - não o gênero. Ou seja, se fosse uma mulher, uma Mãe de Santo a líder de terreiro, muito provavelmente também receberia alta remuneração, como o Pai de Santo recebe, estando assim a remuneração associada ao cargo dentro da hierarquia e não ao gênero.

Para a problematização levantada no parágrafo anterior faz-se necessária a compreensão da estruturação da família de santo e da hierarquia dessa estrutura.

As famílias de santo presentes nas comunidades de terreiro foram historicamente forjadas em torno da figura da Mãe de Santo, como citado na sessão anterior deste artigo (LADES, 1967/ SEGATO, 2005). O regime escravocrata brasileiro agia de forma deliberada na separação dos entes de uma família escravizada. $O$ intuito era a separação dos laços e vínculos familiares para que os processos de amotinamento e revoltas fossem escasseados. Tal estratégia escravocrata fez com que as mulheres e homens negros escravizados criassem a sua própria estratégia de manutenção de vínculos que pode ser visto na própria estruturação das comunidades de terreiro.

Referindo-me a família de santo:

Esta família utiliza os termos da família biológica, como mãe, pai, filhos e filhas, porém é formada a partir de laços construídos nos rituais, especialmente com a iniciação no culto. Assim, temos a Mãe ou Pai de Santo que desenvolvem uma relação vertical com seus filhos e filhas de santo. Para a família de santo as determinações biológicas são irrelevantes, a família é construída a partir do parentesco no santo, ou seja, a partir do vínculo com a Mãe ou Pai de santo derivado da iniciação no culto, sendo essa a forma de organização presente na grande maioria dos cultos afro-brasileiros (OLIVEIRA, 2017. p. 56).

Dentro de uma comunidade de terreiro a família de santo é estruturada hierarquicamente através de um conceito relacional de senioridade (SEGATO, 2003) ou, como denomina Oyèrónkẹ Oyěwùmí, de maioridade (OYEWÙMÍ, 1997/2017). Ou seja, a hierarquia é relacional e não está baseada na prerrogativa do gênero. 
Focando na problematização de gênero como uma categoria universal Oyèrónkẹ Oyěwùmí propõe um questionamento sobre a utilização do feminismo eurocentrado para a compreensão da sociedade Yorubá. Em sua argumentação a autora destaca que para se interpretar a sociedade Yorubá é necessária trazê-la para o centro da discussão e tomá-la como base e não em comparação com os conceitos apresentados pela sociedade ocidental, sejam estes o feminismo eurocentrado ou do patriarcalismo (Oyěwùmí, 1997/2004).

A crítica de Oyěwùmí está pautada na construção do feminismo eurocentrado com base na família nuclear e na universalização da categoria de gênero. Segundo a autora, referindo-se a família nuclear:

Distinções de gênero são fundantes do estabelecimento e funcionamento deste tipo de família. Assim, o gênero é o princípio organizador fundamental da família, e as distinções de gênero são a fonte primária de hierarquia e opressão dentro da família nuclear (OYEWÙMÍ, 2004. p.4).

Faz-se necessária aqui a observação de que Oyěwùmí traz em seu trabalho uma crítica à visão eurocentrada a partir da perspectiva yorubana do sudoeste da Nigéria. Segunda a autora, sobre o conceito de mãe dentro da família nuclear:

Ao teorizar a partir do espaço confinado da família nuclear, não é de se estranhar que as questões de sexualidade automaticamente vêm à tona em qualquer discussão de gênero. Mesmo uma categoria como mãe não é inteligível para o pensamento feminista branco, exceto se a mãe é inicialmente definida como esposa do patriarca. Parece não haver compreensão do papel de mãe independente de seus laços sexuais com um pai. Mães são, antes de tudo, esposas. Esta é a única explicação para a popularidade do seguinte paradoxo: mãe solteira. A partir de uma perspectiva africana e como uma questão de fato, mães por definição não podem ser solteiras. Na maioria das culturas, a maternidade é definida como uma relação de descendência, não como uma relação sexual com um homem (OYEWÙMÍ, 2004. p.5).

A partir dessa problematização levantada por Oyèrónkẹ Oyěwùmí, convido-as a reflexão sobre a problematização da utilização de conceitos externos a comunidade afro-religiosas para compreensão da mesma. A estruturação da família de santo não está atrelada a prerrogativa de gênero, portanto, é fundamental que a complexidade dessas comunidades seja levada em consideração. 
A associação inadvertida entre o trabalho desenvolvido por mulheres dentro dos terreiros e a inferiorização dos trabalhos domésticos desenvolvidos por mulheres em outras esferas pode trazer um erro de interpretação.

Makota Valdina ${ }^{7}$ muito sabiamente nos alerta para a desvalorização de trabalhos que foram desenvolvidos por mulheres negras durante muitos anos como o de lavadeira, passadeira, rendeira, cozinheira, engomadeira e que atualmente são considerados de forma depreciada pela sociedade, tendo em vista que ela é calcada no patriarcado e a relação dessas atividades domésticas é vista como subalternas pela sociedade machista. Isso nos alerta para o fato de que uma simples tradução de papéis lidos como domésticos como depreciados pode nos levar a uma análise rasa da situação. Pois foi a partir dessas formas de trabalho que as mulheres conseguiram ter sua independência financeira e construir seus terreiros e manter unida a sua família de santo.

Além disso, a cozinha lida como um espaço doméstico e depreciado pela colonial modernidade é, dentro dos terreiros, um local sagrado em que, em algumas religiões afro-brasileiras, somente mulheres são convocadas a ocupar. A cozinha é um local do exercício de poder. Quem cozinha tem o poder de alimentar sua ancestralidade, manipular energia e alimentar toda a comunidade e, por isso, as mulheres que desempenham este papel no terreiro não devem ser equivocadamente lidas como executoras de simples afazeres domésticos. A Iyábassé é, portanto, o cargo desempenhado pela mulher responsável pela alimentação sagrada no Candomblé.

Outra situação que deve ser complexificada é o fato de que tanto homens quanto mulheres iniciadas, ou seja, yawo, iniciado ou iniciada no Candomblé Ketu, ou muzenza, iniciado ou iniciada no Candomblé Angola, são chamados e chamadas a cumprirem tarefas como lavar louças, lavar banheiros e cuidar das tarefas da manutenção do terreiro, indistintamente (OLIVEIRA, 2017. p. 58).

A relação com o dinheiro dentro das comunidades de terreiro também merece uma atenção. As relações se dão, em sua maioria, através das trocas de excedentes sendo a troca através de um produto por dinheiro só mais uma das formas possíveis de troca. Essa troca caracteriza-se como troca entre sujeitos e não entre sujeito e objeto e o acúmulo de dinheiro seria, dentro dos princípios da cosmovisão afro-religiosa, uma quebra de Axé, sendo Axé um princípio dinâmico presente em tudo e que pressupõe a

\footnotetext{
${ }^{7}$ Makota Valdina é uma afrorreligiosa de grande atuação dentros dos terreiros, como também é um dos ícones das comunidades afrorreligiosas nas lutas pelos direitos das comunidades de terreiro. Fala disponível em: <https://www.youtube.com/watch?v=qbgoqgoBiKU\&t=311s>
} 
circulação de energia para a manutenção de sua dinamicidade e poder ${ }^{8}$ (NASCIMENTO, 2016, p. 31-33).

Atentemo-nos, portanto, ao fato de que a crítica que por vezes fazemos do patriarcado, o utiliza como conceito da própria crítica que promove, pois o feminismo eurocentrado utiliza-se das características do próprio patriarcalismo para criticá-lo e a ele se opor.

Para as comunidades de terreiro e dentro das religiões afro-brasileiras, não podemos utilizar o patriarcado como medida, pois se trata, como já exposto anteriormente, de uma outra forma de ser, estar e compreender o mundo que não encontra correspondentes na sociedade ocidental.

\section{Mais do que uma conclusão, um chamado para reflexão}

O fato de que há uma influência da sociedade exterior ao terreiro e, por consequência, do patriarcado brasileiro dentro dos terreiros não é negada. A estrutura da sociedade mais abrangente tem como base o patriarcado, a sociedade brasileira foi durante anos, como ainda é, forjada pelo apagamento da história dos povos negros e indígenas no país e sob forte influência ocidental europeia de ser e compreender o mundo e, portanto, é importante atentarmos para como essa influência ocorre e de que maneira é realmente.

Mas, longe de parecer criticar o excelente trabalho desenvolvido por Aída Sarduy, o intuito dessas reflexões é mostrar a diversidade das religiões afro-brasileiras e reforçar o questionamento com relação à perda de poder das mulheres de terreiro. Diante das reflexões suscitadas pelas autoras citadas na última sessão, pode-se compreender a complexidade do tema com relação ao gênero nos terreiros. Para além disso, há de se considerar que as religiões afro-brasileiras não devem ser essencializadas de forma a pensar na unicidade de práticas, tampouco na unicidade de explicações segundo teorias que não necessariamente refletem sobre $\mathrm{o}$ contexto dessas comunidades.

\footnotetext{
${ }^{8}$ Para maiores informações sobre a discussão entre as dinâmicas de troca nos terreiros e a influencia do capitalismo ver em: OLIVEIRA, Ariadne M. Basílio de. Religiões Afro-brasileiras e o Racismo: contribuição para a categorização do racismo religioso. Dissertação (mestrado) Programa de PósGraduação em Direitos humanos e Cidadania do Centro de Estudos Avançados Multidisciplinares da Universidade de Brasília, 2017.
} 
É de suma importância a compreensão dos papéis rituais e sociais realizados nos terreiros de candomblé por mulheres com o objetivo de identificar se há uma hierarquização ou inferiorização das tarefas desempenhadas por mulheres nessas comunidades, identificando, assim, se as elas estão perdendo espaço e poder dentro de suas comunidades e concretizando a compreensão sobre qual lugar as mulheres ocupam dentro das dinâmicas dos terreiros de candomblé atualmente. Para que isso seja feito, convindo-as a refletir sobre a necessidade de complexificar a compreensão dessas comunidades mantendo-as como foco de sua própria análise.

\section{Referências Bibliográficas}

ARRIBAS LOZANO, Alberto. Antropología colaborativa y movimientos sociales: construyendo ensamblajes virtuosos entre sujetos en proceso. Ankulegi, 19, 2015, pp. $59-73$.

BANDEIRA, Lourdes Maria; ALMEIDA, Tânia Mara Campos. "A Transversalidade de Gênero nas Políticas Públicas”. In: Revista do Ceam, v. 2, n. 1, jan./jun. 2013.

BASTIDE, Roger. As Religiões Africanas no Brasil. São Paulo: Livraria Pioneira. 1971.

BHABHA, Homi K. O local da cultura. Belo Horizonte: Ed. UFMG. 1998.

BIDASECA, Karina. "Reconociendo las superficies de nuestras hendiduras. Cartografiando el Sur de nuestros Feminismos". In: Legados, Genealogías y Memorias Poscoloniales en América Latina: Escrituras fronterizas desde el Sur. Karina Bidaseca, Alejandro De Oto, Juan Obarrio y Marta Sierra. Ediciones Godot. Buenos Aires, Argentina, 2013.

BIRMAN, Patrícia. Fazendo Estilo Criando Gêneros: possessão e diferenças de gênero em terreiros de Umbanda e Candomblé no Rio de Janeiro. Rio de Janeiro: EdUERJ, 1995.

Transas e Transes: sexo e gênero nos cultos afro-brasileiros, um sobrevôo. Estudos Feministas, Florianópolis, 13(2): 256, maio-agosto/2005.

CORDOVIL, Daniela. "Sexualidade, gênero e poder: uma análise da participação feminina em políticas públicas para afrorreligiosos em Belém, Pará". PLURA, Revista de Estudos de Religião, ISSN 2179-0019, vol. 4, n² 2, 2013, p. 149-163.

CORREIA, Sandro dos Santos. "A importância das mulheres do candomblé no desenvolvimento de Cachoeira, BA". In: Odeere: revista do programa de pós-graduação em Relações Étnicas e Contemporaneidade - UESB. ISSN 2525- 4715. Ano 2, número 3, volume 3, Janeiro - Junho de 2017.

CRENSHAW, Kimberlé. "Documento para o Encontro de Especialistas em Aspectos da Discriminação Racial Relativos ao Gênero". Estudos Feministas, Ano 10, 1/2002. 
FERRETI, Mundicarmo. Matriarcado em Terreiros de Mina do Maranhão - realidade ou ilusão?. III Encontro de Pesquisadoras/es Maranhenses sobre Gênero, Mulheres e Cidadania - Feminismos, Ciências e Universidade - São Luís, março de 2007.

FRY, Peter. Para inglês ver. Rio de Janeiro: Zahar, 1982.

GESCO- Grupo de estúdios sobre decolonialidad. "Estudios decoloniales: um panorama general”. KULA. In: Antropólogos del Atlántico Sur, n.6, abril, pp. 8-21, 2012.

HERSKOVITS, Melville. "The City of Women" (resenha). In: American Antropologist. 1947.

LANDES, Ruth. A Cidade das Mulheres. Rio de Janeiro: Civilização Brasileira, 1967.

LUGONES, María. “Colonialidad y género". In: Tejiendo de otro modo: Feminismo, epistemología y apuestas descoloniales en Abya Yala / Editoras: Yuderkys Espinosa Miñoso, Diana Gómez Correal, Karina Ochoa Muñoz - Popayán: Editorial Universidad del Cauca, 2014.

NASCIMENTO, Wanderson Flor do. "Sobre os candomblés como modo de vida: Imagens filosóficas entre Áfricas e Brasis". In: Ensaios Filosóficos, Volume XIII Agosto, pp. 153- 170, 2016.

. "Olojá: Entre encontros - Exu, o senhor do mercado". In: DasQuestões, n.4, ago/set, pp. 28- 39, 2016c

OLIVEIRA, Ariadne M. Basílio de. Religiões Afro-brasileiras e o Racismo: contribuição para a categorização do racismo religioso. Dissertação (mestrado) Programa de PósGraduação em Direitos humanos e Cidadania do Centro de Estudos Avançados Multidisciplinares da Universidade de Brasília, 2017.

OYĚWÙMÍ, Oyèrónké. La invención de las mujeres. Una perspectiva africana sobre los discursos occidentales del género. Colombia: Editorial en la frontera, 2017.

. "Conceituando o gênero: os fundamentos eurocêntricos dos conceitos feministas e o desafio das epistemologias africanas". Tradução para uso didático de: OYĚWÙMÍ, Oyèrónké. Conceptualizing Gender: The Eurocentric Foundations of Feminist Concepts and the challenge of African Epistemologies. African Gender Scholarship: Concepts, Methodologies and Paradigms. CODESRIA Gender Series. Volume 1, Dakar, CODESRIA, 2004, p. 1-8

QUIJANO, Aníbal. "Dom Quixote e os Moinhos de Vento na América Latina". In: Estudos Avançados, v.19, n.55, p. 9-31, 2005a

. "Colonialidade do poder, eurocentrismo e América Latina". In: $A$ colonialidade do saber: eurocentrismo e ciências sociais. Perspectivas latinoamericanas Buenos Aires. CLACSO. 2005b 
RAMOS, Arthur. "Pesquisas estrangeiras sobre o negro no Brasil". In: A aculturação negra no Brasil. Rio de Janeiro: Biblioteca pedagógica brasileira, 1942.

RAPPAPORT, Joanne. "Más allá de la escritura: La epistemología de la etnografia en colaboración". In: Revista Colombiana de Antropologia, Volumen 43, enero-diciembre, 2007.

SARDUY, Aída Esther Bueno. El ocaso del liderazgo sacerdotal femenino en el Xangô de Recife: la ciudad de las mujeres que no será. Memoria para optar al grado de doctor. Madrid, 2015.

SEGATO, Rita L. "Género, política e hibridismo en la transnacionalización de la cultura Yoruba”. In: Estudos Afro-Asiáticos, Ano 25, no 2, pp. 333-363, 2003.

- Santos e Daimones: o politeísmo afro -brasileiro e a tradição arquetipal. $2^{\circ}$ ed. - Brasília: Ed. Universidade de Brasília, 2005. 516 p.

"Ciudadania: Por que no? Estado y sociedad en el Brasil a la luz de un discurso religioso afro-brasileño". In: La nación y sus otros. Raza, etnicidad y diversidade religiosa en tiempos de Políticas de la Identidad. Buenos Aires: Prometeo Libros, 2007.

"Gênero e colonialidade: em busca de chaves de leitura e de um vocabulário estratégico decolonial". e-cadernos ces [Online], $18 \mid 2012$, posto online no dia 01 décembre 2012.

. Patriarcado: del borde al centro. Disciplinamiento, territorialidade y crueldad en la fase apocalíptica del capital. VII Conferencia Latino Americana y Caribeña de Cencias Sociales "Transformaciones democráticas, justícia social y procesos de paz." 9-13 novembro. Medellin, Colombia. 2015. Disponível em: < https://www.youtube.com/watch?v=Lq6DJoiUSO8>

La guerra contra las mujeres. Madri: Traficantes de Sueños. 2016

SILVA, Joselina; DOMINGOS, Reginaldo F. "As Religiões Afro-Brasileiras na Voz das Mulheres Lideranças em Juazeiro do Norte". In: Tempo da Ciência (16) 31 : 111$124,1^{\circ}$ semestre 2009.

SILVA, Nadijja; OLIVEIRA, Jéssica; CAMPOS, Zuleica. As lideranças femininas nos terreiros de xangô: um estudo de gênero. III Colóquio de História - Brasil: 120 anos de República. UNICAP. Recife. 9-22 outubro, 2009.

SILVEIRA, Renato da. O candomblé da Barroquinha: processo de constituição do primeiro terreiro baiano de keto. Salvador: Maianga, 2006.

SOUZA, Nadson Nei da Silva de. Mulheres do Axé: da invisibilidade social à visibilidade religiosa. Dissertação de Mestrado apresentada ao programa de Pósgraduação Stricto Sensu de Relações Etnicorraciais como parte dos requisitos necessários à obtenção do título de Mestre em Relações Etnicorraciais. CEFET, Rio de Janeiro. 2014. 
Revista Calundu -Vol.4, N.1, Jan-Jun 2020

VILELA, Ana Laura S. İyálodè Iyà Orò: Uma análise das lideranças femininas na criação dos direitos das comunidades tradicionais de terreiro. Trabalho apresentado na $30^{\text {a }}$ Reunião Brasileira de Antropologia, realizada entre os dias 03 e 06 de agosto de 2016, João Pessoa/PB.

Recebido em: 10/05/2020

Aceito em: 14/05/2020 